\title{
SITUS INVERSUS TOTALIS - A RARE CASE REPORT
}

\author{
Aparna Patange1, Ajinkya Bahulekar², Piyush Prajapati3 ${ }^{3}$ Srikant Kandagatla4, Omkar Patil ${ }^{5}$
}

${ }^{1}$ Assistant Professor, Department of Internal Medicine, Krishna Institute of Medical Sciences, Karad.

${ }^{2} 3^{\text {rd }}$ Year Resident, Department of Internal Medicine, Krishna Institute of Medical Sciences, Karad.

$3^{3}$ rd Year Resident, Department of Internal Medicine, Krishna Institute of Medical Sciences, Karad.

${ }_{4}^{4}$ rd Year Resident, Department of Internal Medicine, Krishna Institute of Medical Sciences, Karad.

${ }^{5} 3^{\text {rd }}$ Year Resident, Department of Internal Medicine, Krishna Institute of Medical Sciences, Karad.

\section{ABSTRACT}

\section{BACKGROUND}

A 60 years old previously asymptomatic female was admitted with accelerated hypertension and she was incidentally found to have mirror images of normal anatomical organs in chest and abdomen called situs inversus totalis. Situs inversus totalis is a congenital anomaly characterized by transposition of abdominal viscera associated with dextrocardia. Complete situs inversus is a rare syndrome of autosomal recessive inheritance. The anatomic, pathologic, embryologic and aetiology of complete situs inversus and related abnormalities are presented in this case with special emphasis to genetic correlation.

\section{KEYWORDS}

Accelerated Hypertension, Complete Situs Inversus, Congenital Anomaly, Dextrocardia, Transposition of Abdominal Viscera.

HOW TO CITE THIS ARTICLE: Patange A, Bahulekar A, Prajapati P, et al. Situs inversus totalis - a rare case report. J. Evolution Med. Dent. Sci. 2017;6(4):343-346, DOI: 10.14260/Jemds/2017/77

\section{BACKGROUND}

Situs inversus totalis is a congenital condition, in which the major visceral organs are reversed from their normal position. The situs inversus is present in $0.01 \%$ of the population. It is an autosomal recessive genetic condition, sometimes it can be $\mathrm{X}$-linked and also found in identical twins.[1,2] The persons with situs inversus totalis are usually asymptomatic and have a normal life expectancy. The situs inversus totalis has been estimated to occur once in about 6000 - 8000 live births. Situs inversus with levocardia[3] is another rare condition occurring in 1 in 22,000 of general population, in which the heart is found on normal side of thorax.

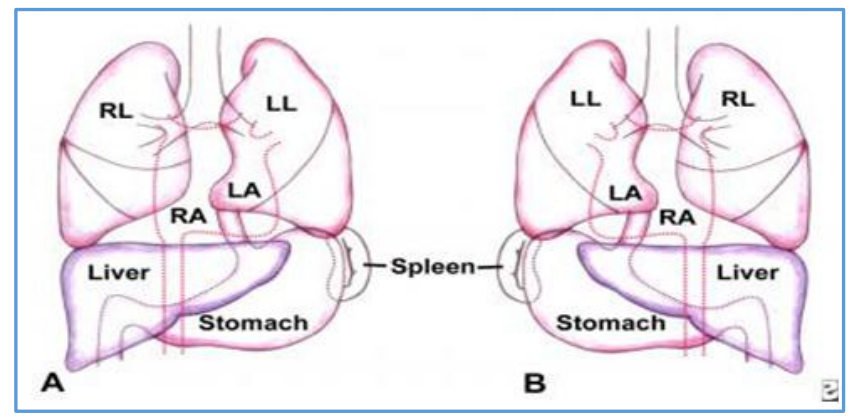

\section{CASE REPORT}

A 60 years old female patient was admitted with a history of headache and giddiness of 2 days' duration. She did not give any history of significant illness in the past. There was no significant illness in the family. On examination, she was conscious, oriented, her pulse rate was 80 beats per minute, BP was 180/100 mmHg in supine and upright position. She did not have any signs of focal neurodeficit.

Financial or Other, Competing Interest: None.

Submission 27-11-2016, Peer Review 01-01-2017,

Acceptance 06-01-2017, Published 12-01-2017.

Corresponding Author:

Dr. Piyush Prajapati,

IHR Hostel,

Krishna Institute of Medical Sciences, Karad.

E-mail: prajapatipiyush786@gmail.com

DOI: $10.14260 /$ jemds $/ 2017 / 77$
Her investigations revealed a haemoglobin of $12.4 \mathrm{gm} \%$, total leukocyte count of $10100 / \mathrm{mm} 3$ with polymorphs of $86 \%$, lymphocytes $12 \%$, PCV $40.6 \%$. Blood sugar, renal function tests, liver function tests and sr. electrolytes were within normal limits. She was not immunosuppressed. Chest radiogram showed Dextrocardia. Ultrasound abdomen revealed liver in left hypochondrium, spleen in right hypochondrium. Inferior vena cava noted left to the aorta, that is features of situs inversus totalis. Her ECG revealed inversion of $\mathrm{P}$ waves in leads I and aVL, dominantly negative QRS waves in leads I, V1-V6, extreme QRS axis, flattened T waves in aVR and inverted $\mathrm{T}$ waves in lead $\mathrm{I}$ and aVL. The features suggesting dextrocardia. Her 2D Echo revealed Dextrocardia with normal sized cardiac chambers and normal LV function. With the clinical and investigation results, a diagnosis of situs inversus totalis was made. She was started on calcium channel blockers for her hypertension. She was completely asymptomatic till date.

\section{Left Sided Leads}

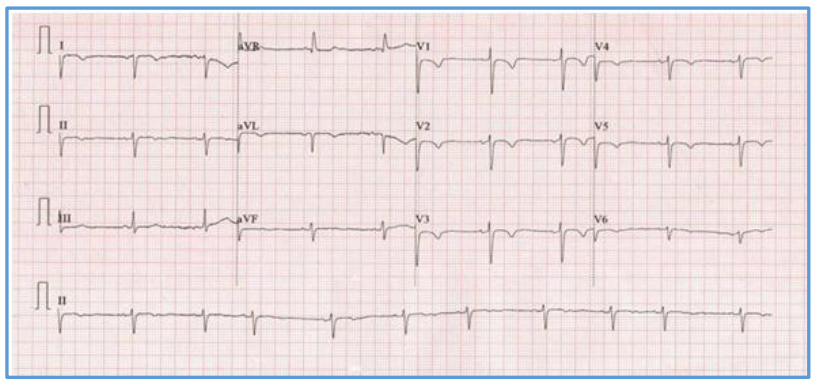

\section{Right Sided Leads}

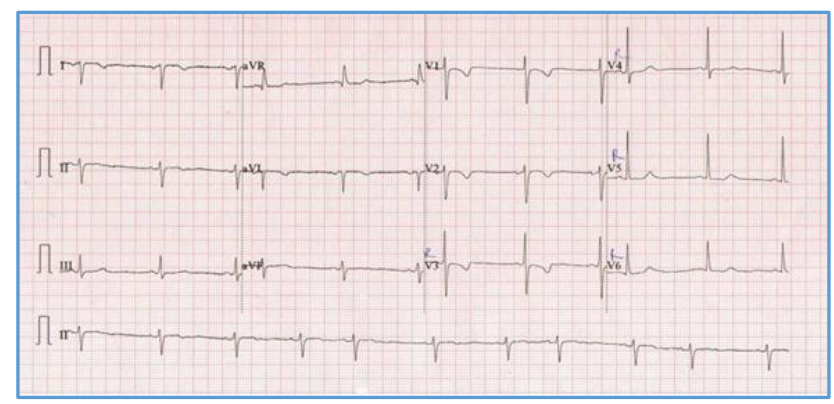




\section{Chest Radiogram}

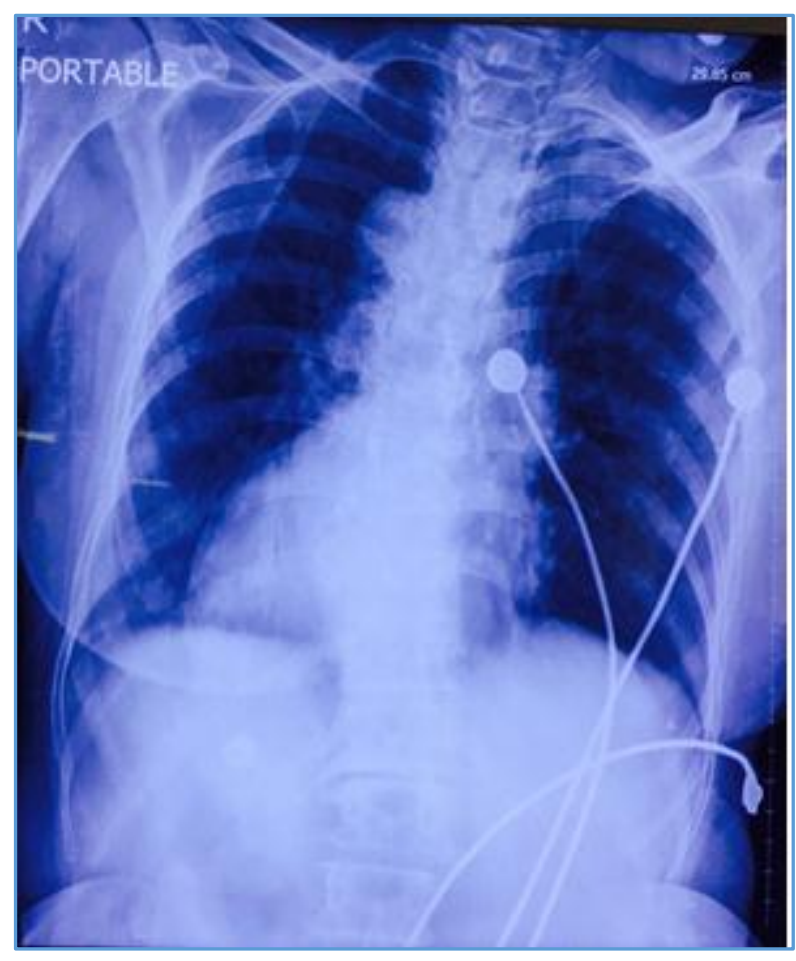

USG Abdomen and Pelvis

- Liver in left hypochondrium.

- Spleen in right hypochondrium.

- Features s/o situs inversus totalis.

\section{CT Abdomen and Pelvis}
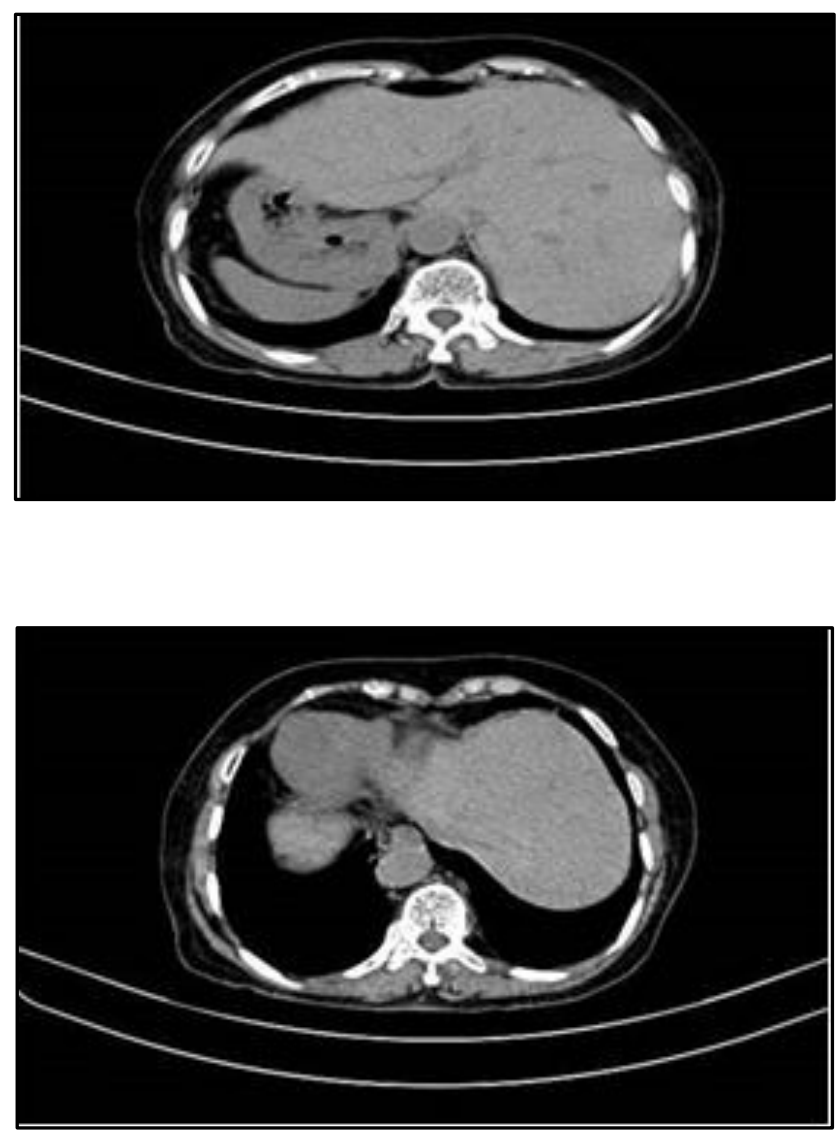
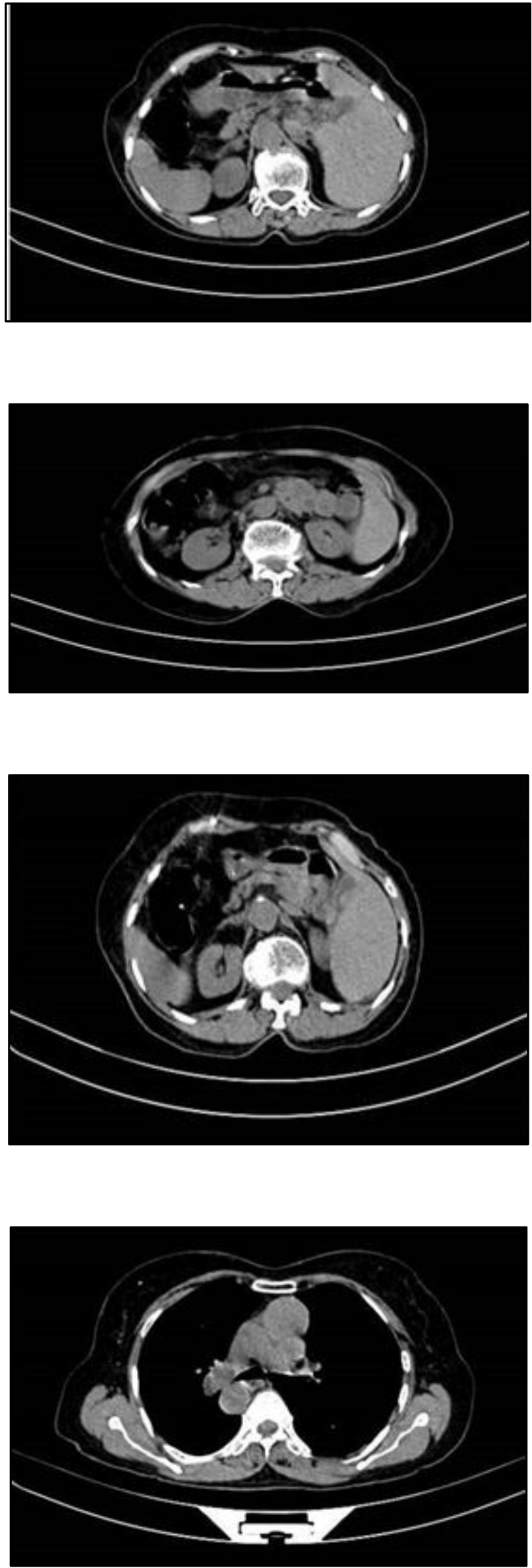


\section{D Echo}
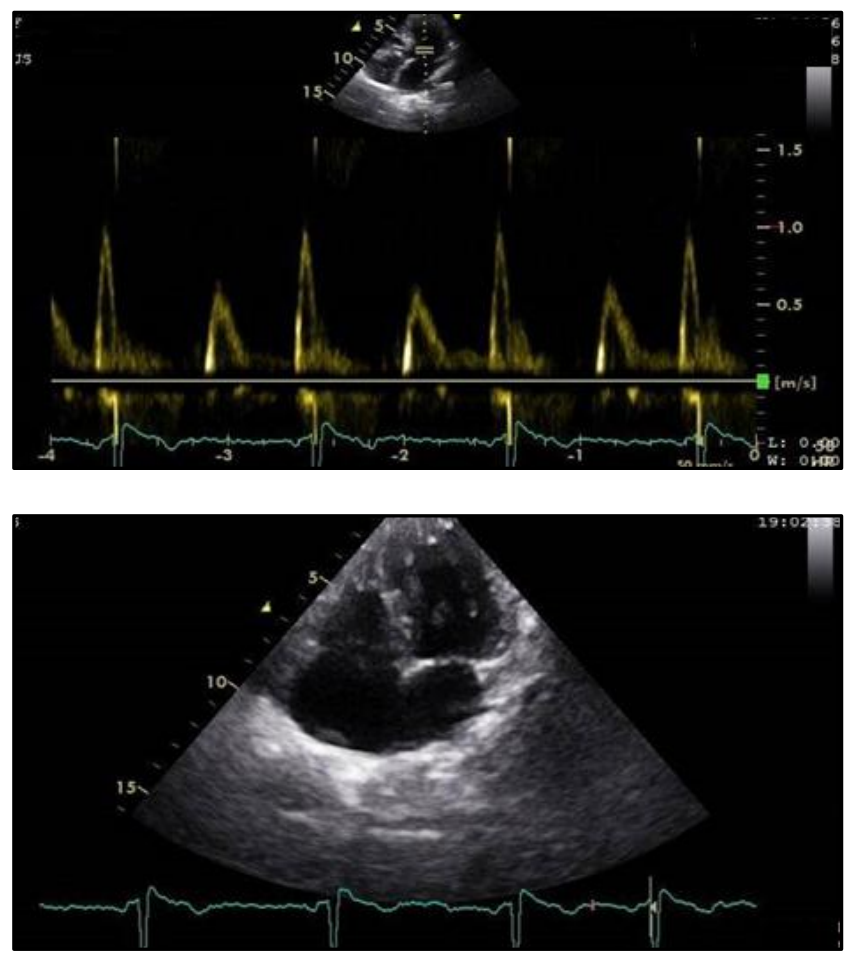

\section{DISCUSSION}

Mathew Baillie first described situs inversus totalis in early $20^{\text {th }}$ century. Distribution is same for both genders (1:1) and there is no difference between races. Rarely situs inversus can run in families, but most often it is an isolated and accidental event occurring in an individual for the first time in family.

In human and in vertebrates, anatomic asymmetry is established during embryogenesis. The left-right axis is determined at the beginning of the embryonic development with the formation of the dorso-ventral and cephalocaudal axes. The cardiac tube curve to the right is the first sign of asymmetry. The left-right gradient has been established at cellular level. The left-right relation of asymmetric viscera is conserved; it is known as situs solitus and when there is complete inversion of the lateralisation of the organs (mirror image); it is known as situs inversus totalis. $[4,5,6,7]$

Recent studies suggest that left-right asymmetry defects to be due to genetic abnormalities in lefty genes, nodal genes and ZIC 3, ACVR2B and Pitxz genes. Mutation of genes present on chromosome $12 .[4,5,6,7]$ The individuals with situs inversus and phenotypically unimpaired and can lead normal healthy lives without any complications related to their medical conditions.

Situs inversus can be classified further into situs inversus with levocardia or situs inversus with dextrocardia. The classification of situs is independent of the cardiac apical position. The terms levocardia and dextrocardia indicate the direction of the cardiac apex at birth, but not the orientation of the cardiac chambers. In levocardia, the base to apex axis is towards the left and reverses in case of dextrocardia. Isolated dextrocardia is situs solitus with dextrocardia. The cardiac apex points to the right, but the viscera are otherwise in their usual positions. Situs inversus dextrocardia is situs inversus totalis because of the cardiac position as well as the atrial chambers and reversed abdominal viscera. $[1,2,3,8,9,10]$ Cardiac situs is determined by the location of the atria. In both situs solitus and situs inversus, the ventricles may present in two positions.

1. D-loop or right sidedness, that is right ventricle is anterior and to the right of the left ventricle (normal).

2. L-loop or left sidedness, right ventricle is posterior and to the left of left ventricle (inversion of ventricles). Dextrocardia is cardiac malposition in which the heart is in the right hemithorax with the base to apex axis pointing to right[11]; $3 \%$ of people with situs inversus totalis have some form of congenital heart disease.[12,11] About $25 \%$ of individuals with situs inversus totalis have an underlying condition known as primary ciliary dyskinesia.

PCD is the dysfunction of the cilia that manifests itself during the development of foetus. Situs inversus with PCD together known as Kartagener syndrome characterised by triad of situs inversus, chronic sinusitis and bronchiectasis. ${ }^{[13,14,15,16,17]}$

\section{CONCLUSION}

Situs inversus totalis is mostly an incidental finding. Most individuals are unaware of having situs inversus totalis in them and they come to know during screening investigations for unrelated illness. Though Kartagener syndrome can be associated with situs inversus totalis, so physician must be vigilant in suspected cases and should take help of radiological investigations to confirm the diagnosis. Situs inversus also complicates organ transplantations as donor organs will almost certainly come from situs solitus donors.

\section{REFERENCES}

[1] Yokoyama T, Copeland NG, Jenkins NA, et al. Reversal of left-right asymmetry: a situs inversus mutation. Science 1993;260(5108):679-82.

[2] Gedda L, Sciacca A, Brenci G, et al. Situs viscerum specularis in monozygotic twins. Acta Genet Med Gemellol (Roma) 1984;33(1):81-5.

[3] Gindes L, Hegesh J, Barkai G, et al. Isolated levocardia: prenatal diagnosis, clinical importance, and literature review. J Ultrasound Med 2007;26(3):361-5.

[4] Kosaki R, Gebbia M, Kosaki K, et al. Left-right axis malformations associated with mutations in ACVR2B, the gene for human activin receptor type IIB. Am J Med Genet 1999;82(1):70-6.

[5] Ryan AK, Blumberg B, Rodriguez-Esteban C, et al. Pitx2 determines left-right asymmetry of internal organs in vertebrates. Nature 1998;394(6693):545-51.

[6] Piedra ME, Icardo JM, Albajar M, et al. Pitx2 participates in the late phase of the pathway controlling left-right asymmetry. Cell 1998;94(3):319-24.

[7] Dextrocardia with Situs Inversus. WebMD. Aug. 8, 2007. http://www.webmd.com/heart-disease/dextrocardiawith-situs-inversus

[8] Fung TY, Chan DL, Leung TN, et al. Dextrocardia in pregnancy: 20 years' experience. J Reprod Med 2006;51(7):573-7.

[9] Sirin BH, Kurdal AT, Iskesen I. Congenitally corrected transposition of the great arteries plus dextrocardia operated with an unusual operative technique. Thorac Cardiovasc Surg 2008;56(6):367-9. 
[10] Hagler DJ. Cardiac malpositions and abnormalities of atrial and visceral situs. In: Adams FA. (eds). Heart Disease in Infants, Children and Adolescents. $5^{\text {th }}$ edn. Baltimore: Williams and Wilkins 1995:1307-36.

[11] Silverman NH. An ultrasonic approach to the diagnosis of cardiac situs, connections, and malpositions. Cardiol Clin 1983;1(3):473-86.

[12] Fuster, Valentin, Alexander, et al. The Heart. Chapter 81: Cardiovascular diseases caused by genetic abnormalities.

[13] Ferrero GB. A submicroscopic deletion in Xq26 associated with familial situs ambiguus. Am J Hum Genet 1997;61(2):395-401.
[14] Kinney TB, DeLuca SA. Kartagener's syndrome. Am Fam Physician 1991;44(1):133-4.

[15] Schidlow DV. Primary ciliary dyskinesia (the immotile cilia syndrome). Ann Allergy 1994;73(6):457-68; quiz 468-70.

[16] Yarnal JR, Golish JA, Ahmad M, et al. The immotile cilia syndrome: explanation for many a clinical mystery. Postgrad Med 1982;71(2):195-7, 200-2, 209-11 passim.

[17] Gierich J, Otto J, Walk H, et al. Primary ciliary dyskinesia in situs inversus without bronchiectasis. Pneumologie 1997;51(12):1127-32. 